\title{
Graus de participação democrática no uso da Internet pelos governos das capitais brasileiras
}

\section{Sivaldo Pereira da Silva}

Universidade Federal da Bahia

\section{Resumo}

Este artigo tem o objetivo de analisar se e como os governos municipais das capitais brasileiras estão empregando as novas tecnologias da comunicação e informação (TICs), especificamente a internet, para melhorar a participação do cidadão nos assuntos públicos. O estudo foi baseado no emprego político das TICs segundo cinco graus de participação democrática. Foram analisados os vinte e quatro portais (sítios na rede mundial de computadores) das capitais brasileiras presentes na rede mundial de computadores.

Palavras-chave: comunicação política, democracia digital, internet, governo municipal.

\begin{abstract}
The present article has the goal of analyzing if and how governments of Brazilian major towns are employing the TCl's, in order to improve the levels of civil engagement in the public issues. The study was based on the existence of five degrees of democratic engagement, in the political appropriations of TCl's. We have analyzed 24 sites located in the internet.
\end{abstract}

Key words: political communication, digital democracy, internet, local government. 
SILVA, S. P. Graus de participação democrática no uso da Internet...

O desenvolvimento de tecnologias digitais de comunicação no final do século XX e seu processo de massificação, ainda em andamento, têm reforçado um importante debate sobre participação civil nas democracias liberais contemporâneas. Estes novos meios possuem potencialidades técnicas de interação mais horizontais, quando comparados aos meios anteriores como a televisão e o rádio. Teóricos, políticos, governos e imprensa têm disseminado a idéia de que, diante deste potencial interativo, haveria agora novas possibilidades de melhorar a participação do cidadão nos negócios públicos, na tomada de decisão política e até mesmo, em alguns casos, de fazer com que a própria esfera civil tome as decisões até então restritas à esfera política.

Diante deste quadro, surge um problema central: essas novas tecnologias da informação e comunicação (TICs) estariam, de fato, possibilitando maior participação democrática nas cidades contemporâneas? Se há participação democrática, de que forma isto ocorre?

Nota-se, mundialmente, que uma parte significativa das experiências e projetos que tentam explorar a potencialidade política das TICs é pautada nas localidades municipais. Isto se dá porque a dimensão social das cidades serve como projeto-piloto, por se tratarem de unidades políticas mais concentradas geograficamente e que refletem, de modo mais imediato, as relações civis. 0 objetivo deste artigo é analisar se os governos das capitais brasileiras estão empregando essas tecnologias, especificamente a internet, para aumentar a participação do cidadão nos negócios públicos e as formas como essa participação estaria ocorrendo. Tendo em vista este fim, tomou-se como corpus empírico os 24 portais oficiais das capitais brasileiras presentes hoje na rede mundial de computadores $^{1}$. Este recorte do problema é representativo por três razões fundamentais: (1) o poder executivo é uma das instâncias que detém de forma significativa a produção da decisão política; (2) as capitais dos estados que constituem a República Federativa do Brasil são representativas da diversidade sócio-política e econômica do país; (3) embora esta utilização das TICs possa ocorrer de forma diversa, a internet é o meio mais empregado atualmente pela instância governamental brasileira.

O trabalho está divido em três partes. Inicialmente, está delineado um breve quadro teórico sobre as diferentes visões em torno das potencialidades políticas das TICs e os modelos de democracia hoje predominantes no ciberespaço. Em seguida, está proposta a organização do debate sobre democracia digital a partir da idéia de "graus de participação democrática". Por último está apresentada uma análise baseada em dados empíricos ${ }^{2}$ sobre os graus

\footnotetext{
${ }^{1}$ Portais em operação na internet no período de novembro e dezembro de 2004.

2 As informações empíricas que servem como subsídio para esta análise foram coletadas por pesquisa baseada em incursões orientadas nos respectivos portais. Para tanto, foi desenvolvida uma planilha de
} 
de democracia digital existentes hoje no Brasil, no que diz respeito ao uso da internet pelos governos das capitais brasileiras.

\section{As visões sobre a potencialidade política das TICs e os modelos de democracia no ciberespaço}

Quase toda a literatura sobre democracia digital reconhece a potencialidade comunicativa das TICs (principalmente a interação em larga escala). Esta possibilidade tecnológica de interação horizontal em massa estaria apta a interferir na relação do cidadão com seu respectivo governo, o que repercutiria em mudanças no modo de operação da política contemporânea. No atual debate sobre o tema, as divergências entre os autores podem ser configuradas fundamentalmente de dois modos:

Sobre o tipo de repercussão - Nem sempre as conseqüências das TICs são vistas de forma positiva. Apesar de um certo otimismo predominante por parte de alguns autores (NEGROPONTE, 1995; RHEINGOLD, 1996; LEVY, 1995 e 1999; MITCHELL, 2002 e 2004; TOFFLER, 1995), existe hoje um debate mais cauteloso em relação ao verdadeiro alcance da intervenção transformadora destas tecnologias, principalmente no que diz respeito à política (COLEMAN, 1999a; HAGUE e LOADER, 2002; KINDER, 2002; LIEVROUW e LIVINGSTONE, 2002; MAIA, 2002; MALINA, 1999; PAPACHARISSI, 2002; SCHMIDTKE, 1998; SPINELLI, 2000; WHILHELM, 1999; WEBSTER, 2002). Para alguns teóricos (MALINA, 1999; SCHMIDTKE, 1998; COLEMAN, 1999a e 1999b), as TICs seriam marcadas por uma natureza ambígua e o seu uso para fins políticos benéficos depende, sobretudo, não da sua capacidade interativa, mas do modo de apropriação social. Um terceiro grupo (DEAN, 1997; BUCHSTEIN, 1997; WOLTON, 2001) vê mais efeitos negativos do que conseqüências positivas ou ambigüidades nas TICs.

Sobre a intensidade de repercussão - As visões mais positivas sustentam predominantemente a idéia de que o uso em larga escala das TICs seria capaz de transformar de modo significativo as relações sociais e políticas, possibilitando maior fluxo de informação, reforçando laços comunitários, revigorando a participação do cidadão e gerando, com isso, novas formas de relações com o poder. Aqui, não se fala explicitamente em um novo sistema político (que suplantaria o sistema

coleta de dados preenchida mediante navegação on-line nos sítios estudados, visando encontrar e tipificar elementos de conteúdo textual, ferramentas de interação, disposição gráfica; buscando análises comparativas entre os portais analisados, apontando convergências, distinções, padrões e mapeando características gerais que podem caracterizar a existência destes graus de participação democrática no uso da internet pelos governos municipais das capitais brasileiras. 
democrático moderno atual), mas esta visão está bastante afinada com a idéia de uma "revolução digital" ou o surgimento de uma "sociedade da informação".

Os outros grupos de autores configuram uma posição bem mais moderada, limitando estas transformações ao nível de um rearranjo do sistema democrático liberal, admitindo repercussões importantes (como maior poder de participação do cidadão na deliberação dos negócios públicos ou, no caso das visões mais negativas, maior controle pelas forças de mercado), mas não tão significativas a ponto de se afinarem com a idéia de uma "revolução".

Além destas visões distintas sobre a potencialidade política das TICs, é possível ainda localizar diferentes retóricas que disputam o modelo de democracia no ciberespaço. Dahlberg nota a existência de três segmentos predominantes: (1) um modelo individualista-liberal; (2) um modelo comunitarista; e (3) um modelo deliberacionista. Para o autor:

"Estes três segmentos de democracia eletrônica são distintos por seus respectivos entendimentos de legitimidade democrática. Para o individualismo liberal, um modelo democrático ganha legitimidade quando fornece expressão aos interesses individuais. Para o comunitarismo, um modelo democrático é legitimado por realçar o espírito e valores comunais. Para a democracia deliberativa, um modelo democrático é legitimado por sua facilitação do discurso racional na esfera pública. Todas as três posições podem ser identificadas dentro da prática e retórica na democracia-internet" (DAHLBERG, 2001, p. 158) ${ }^{3}$.

O debate sobre o emprego político das TICs no sistema democrático contemporâneo apresenta uma variação de visões sobre as promessas e o modo de existência de uma democracia mediada por artefatos tecnológicos. Do ponto de vista prático, diversos experimentos, projetos, relatórios e discursos, envolvendo esse emprego das TICs, têm sido intensamente produzidos pelo mundo, assumindo formas distintas. Embora o discurso de legitimidade dessas iniciativas possa aparecer sob o rótulo genérico da "democracia digital", percebem-se, na verdade, diferenças importantes entre essas experiências". Esses projetos assimilam os

\footnotetext{
3 Tradução própria do original em inglês: "These three electronic democracy camps are distinguished by their respective understandings of democratic legitimacy. For liberal individualism, a democratic model gains legitimacy when it provides for the expression of individual interests. For communitarianism, a democratic model is legitimated by enhancement of communal spirit and values. For deliberative democracy, a democratic model is legitimated by its facilitation of rational discourse in the public sphere. All three positions can be identified within Internet-democracy rhetoric and practice".

4 Democracia digital (ou "ciberdemocracia") não é um termo exato porque sugere, a primeira vista, uma falsa idéia de uma nova forma de democracia. Porém, é útil atualmente para se referir ao conjunto de
} 
discursos sobre o potencial político das TICs e os modelos de democracia predominantes hoje no ciberespaço, dando mais atenção ou menos ênfase a determinados aspectos. O problema é que o termo "democracia digital" serve para rotular experiências distintas, ainda que de alguma forma democráticas. Esta variação de sentido, reivindicado pelos diversos discursos e experimentos, pode ser pensada a partir da percepção da existência de graus de participação democrática. A próxima seção deste trabalho propõe esse ordenamento, tipificando a participação na democracia digital em cinco graus.

\section{Graus de participação democrática e TICs}

Nas variações do debate sobre democracia digital, o que está em jogo é a busca de maior participação da esfera civil nos processos de produção de decisão política. Esta participação pode assumir diversos graus, e sua intensificação seria o imaginário da democracia direta de inspiração grega. Gomes propõe a existência de cinco graus de participação popular no emprego das TICs, que podem contemplar as diferentes compreensões da democracia, sobre os quais os experimentos e discursos poderiam ser enquadrados (GOMES, 2004b):

a) Primeiro grau de democracia digital - pode ser caracterizado pela ênfase na disponibilidade de informação e na prestação de serviços públicos. As TICs e o ciberespaço (incluiu-se a internet) seriam instrumentos democráticos na medida em que circulam informações governamentais genéricas e melhoram a prestação de serviços públicos. O pressuposto neste grau está alicerçado no fluxo de interação predominantemente de mão única: o governo disponibiliza informações ou torna a prestação de serviços mais eficiente, através do emprego destas tecnologias de comunicação. Falar em primeiro grau de democracia significa que há uma ênfase na eficiência instrumental da relação política. No caso específico da relação política entre Estado e cidadão, prevalecem dois papéis claros: (1) o papel de um governo que busca suprir as necessidades de informação básica, serviços e bens públicos ao cidadão (como saúde, transporte, segurança, saneamento básico, facilidade no pagamento de impostos, desburocratização etc.); e (2) o papel de um cidadão que aguarda receber, sem transtornos e com rapidez (em casa, se for possível), esses serviços públicos oferecidos. A figura do cidadão se confunde, assim, com a figura de consumidor, sustentando uma tensão entre dois interesses distintos (GANDY, 2002, p. 453). Esses papéis geraram um tipo de relação entre o governo e as TICs no qual prevalece a busca por produtividade e otimização da máquina estatal.

discursos, teorizações e experimentações que empregam as TICs para mediar relações políticas, tendo em vista as possibilidades de participação democrática nos sistemas políticos contemporâneos (e não para denominar, a princípio, uma prática democrática radicalmente inovadora). 
Sobretudo, os governos irão tratar as TICs e o seu know-how de uso da mesma forma como as empresas tratam os bens de capital e a racionalização para incrementar a produção (FREY, 2002, p. 143).

b) Segundo grau de democracia digital - consiste no emprego das TICs para colher a opinião pública e utilizar esta informação para a tomada de decisão política, e na configuração de "um Estado que consulta os cidadãos pela rede para averiguar a sua opinião a respeito de temas da agenda pública" (GOMES, 2004b, p. 6). Aqui, o emprego das TICs terá papel próximo ao de um "canal de comunicação", embora a emissão continue predominantemente de mão única: o governo não cria um diálogo efetivo com a esfera civil, mas emite sinais para o público a fim de receber algum tipo de retorno. A abertura governamental à participação popular se limita em criar tais canais de sondagem de opinião sobre determinados assuntos públicos, não significando necessariamente que esta opinião aferida será plenamente acatada em todos os campos da produção da decisão política.

c) Terceiro grau de democracia digital - é representado pelos princípios da transparência e da prestação de contas (accountability), gerando uma maior permeabilidade da esfera governamental para alguma intervenção da esfera civil. Este princípio produzirá uma maior preocupação na responsabilidade ${ }^{5}$ política e, com isso, um maior controle popular sobre as ações governamentais.

A publicidade de informações aqui é significativamente diferente da publicidade de informações do primeiro grau: no grau mais elementar (o primeiro), a informação é claramente menos preocupada em demonstrar transparência dos atos de concernência pública e menos preocupada com a formação e as repercussões da opinião pública. A publicidade, neste terceiro grau, é voltada para fortalecer a cidadania, concentrando energias na configuração de uma esfera governamental disposta a "evitar" a prática do segredo ${ }^{6}$. A permeabilidade política deste grau em relação à esfera civil também difere da porosidade do grau anterior. No caso do segundo grau, a porosidade política está restrita à recepção da opinião

\footnotetext{
5 O termo "responsabilidade" deve ser compreendido aqui em seu significado mais lato: ato de responder. Carrega o mesmo sentido do termo accountability, em língua inglesa. Ou seja, a obrigação política em dar razão (respostas), de prestar contas publicamente.

6 Como explica Gomes, "um dos grandes fantasmas a assombrar a democracia é a idéia de governo invisível, a idéia de que o Estado estaria sob o domínio de sujeitos não-autorizados. Eis porque o público não gosta de composições secretas, montadas justamente para enclausurar a esfera política e 'protegê. la' do seu olhar“ (GOMES, 2004a, p. 120). Importante notar que a prestação de contas também é um tipo de exposição de informação, como no primeiro grau. Porém, diferentemente deste grau mais elementar, a informação é potencialmente mais efetiva do ponto de vista da ação democrática da esfera civil porque demanda explicação e justificativa da esfera política sobre seus atos em relação aos negócios públicos. Existe aqui uma categoria de informação que gera maior controle civil sobre os atos governamentais.
} 
do público e a predisposição em considerá-la no processo de tomada de decisão política. No caso deste terceiro grau, esta permeabilidade ocorrerá mediante o controle público das ações governamentais propiciado pela transparência de suas ações. Apesar desta porosidade ser mais efetiva do ponto de vista da participação da esfera civil, é importante ressaltar que, neste terceiro grau, a produção da decisão ainda permanece, em última instância, restrita à esfera política.

d) Quarto grau de democracia digital - está baseado na "democracia deliberativa". Consiste na criação de processos e mecanismos de discussão, visando o convencimento mútuo para se chegar a uma decisão política tomada pelo próprio público, definindo práticas mais sofisticadas de participação democrática. Como explica Dahlberg (2001, p. 167), a democracia deliberativa requer mais interação democrática; é baseada no diálogo aberto e livre onde participantes propõem e desafiam reivindicações e argumentos sobre problemas comuns. Neste processo, indivíduos privados se tornam cidadãos orientados publicamente.

Em uma perspectiva de democracia representativa, este grau pode ser considerado o mais intenso em termos de participação popular, porque ele ainda mantém uma esfera política profissional em face da esfera civil. Esta participação requer um conjunto de princípios, em grande parte inspirado no conceito de esfera pública (GUTMANN e THOMPSON, 1996, p. 12). Diversos autores (COLEMAN, 1999b; DAHLBERG, 2001; FREY, 2002; GUTMANN e THOMPSON, 1996; RICHARD, 1999) defendem princípios deliberacionistas visando uma participação ampliada na produção da decisão política nas democracias contemporâneas.

É preciso notar que a esfera política permanece ainda como agente importante nos processos de tomada de decisão, mantendo o seu papel de representação política. Porém, diferentemente dos graus anteriores, este quarto grau tira a esfera civil do papel de consulta e a coloca, juntamente com a esfera política, como agente de produção da decisão política. A participação popular se torna mais real em termos práticos.

e) Quinto grau de democracia digital - Se o quarto grau de democracia digital é o mais intenso do ponto de vista da participação civil nos negócios públicos, o quinto grau é necessariamente o mais idealista na escala de participação civil, e a sua implementação acarretaria uma mudança significativa no modelo democrático. Neste último grau, as TICs teriam uma função fundamental: retomar o antigo ideal da democracia direta 7 . Embora o quarto grau também defenda um fim mais ou menos similar - o aumento da participação direta da esfera civil na produção da

\footnotetext{
7 Grossman (apud HALE et al., 1999, p. 97) explica que, no caso norte-americano, é possível localizar discursos sobre os quais as novas tecnologias da informação estariam aptas para transformar a natureza da atividade política, inspirando-se nos ideais da democracia direta das cidades-estados da Grécia antiga.
} 
decisão política - ele se preocupará com os processos de deliberação ${ }^{8}$, mantendo a esfera política em seu papel de representatividade. No caso específico deste quinto grau, embora também possa haver processos de deliberação (no sentido de discussão racional), a tomada de decisão não passa por uma esfera política representativa: a esfera civil ocupa o lugar da esfera política na produção da decisão. A ênfase aqui está no fato de que só argumentar não seria suficiente: é preciso deixar que o povo decida. Isto significaria "um estado governado por plebiscito" (GOMES, 2004b, p. 6). Numa democracia digital de quinto grau, prevalece a idéia de que, com as possibilidades interativas em massa das novas tecnologias da comunicação, a decisão deveria estar assim transferida diretamente para a esfera civil. Por estar fortemente baseado no modelo da democracia direta, este grau enfrenta sérios problemas pragmáticos e teóricos para sua implementação. Se levado a cabo isoladamente, sem observar suas possíveis repercussões, a exacerbação de alguns elementos pode gerar um tipo de autoritarismo sustentado pela demagogia ou populismo político. Para alguns autores, esta perspectiva propicia perigos como um público mal informado, propenso a um novo tipo de populismo tecnológico ou, ainda, poderia gerar uma "democracia de apertar botão" (MOORE, 1999, p. 56; COLEMAN, 1999a; MALINA, 1999, p. 24).

Esses graus não devem ser compreendidos como "excludentes" entre si. Também não devem ser vistos de forma rígida como parâmetros estanques. Sobretudo, são úteis para organizar o debate sobre o emprego das TICs nos sistemas democráticos contemporâneos, as variadas formas de se utilizar o rótulo da democracia digital, as concepções, os autores e o grande volume bibliográfico sobre o tema. Embora, em princípio, um grau não inclua necessariamente um outro grau, um projeto pode situar-se entre graus, estando mais propenso para um determinado grau sob um aspecto e para outro grau sob outro, já que os fenômenos não são rigorosamente homogêneos e as iniciativas nem sempre constituem um sistema unitário.

A percepção de algum desses graus na implementação da democracia digital leva em conta um olhar cuidadoso: a existência de elementos de determinados graus não significa que exista, de fato, uma democracia digital. Significa que existem indícios "graduantes" (e não determinantes) de um ideal democrático mediado por tecnologias da comunicação e informação. Este cuidado serve para, inclusive, perceber as lacunas e os problemas de alguns discursos e experimentos, que reivindicam a legitimidade democrática, quando propiciam apenas um nível elementar dos ideais da ciberdemocracia.

\footnotetext{
${ }^{8}$ Com condições de discussão, com elementos que façam a decisão política ser razoável e, ao mesmo tempo, legitimamente construída por indivíduos orientados pelo interesse público.
} 


\section{Graus de participação democrática no uso da internet pelos governos das capitais brasileiras}

As cidades têm sido alvos freqüentes de importantes projetos de ciberdemocracia no mundo. Quando tomamos como base a análise de como estes graus estão estabelecidos no universo das principais cidades brasileiras, especificamente das 24 capitais com portais em operação na rede, é possível detectar a existência de três graus de democracia digital no uso da internet pelos referidos governos: respectivamente, o primeiro, segundo e terceiro grau. Não é possível detectar elementos característicos do quarto e do quinto grau. Neste sentido, nota-se a existência de alguns aspectos relevantes. Primeiramente, há uma predominância clara do primeiro grau com característica "informativa". Este é, efetivamente, o único grau que está mais ou menos estruturado, ou melhor, em via de consolidação. Ainda assim, como mostra a Tabela 1, ele é caracterizado predominantemente pelo viés informativo. Os elementos de prestação de serviços, um outro aspecto que também caracteriza o primeiro grau, ocorrem de maneira menos freqüente nos sítios analisados: aparecem em quantidade menor e são direcionados predominantemente para a relação entre fazenda pública (Estado arrecadador) e contribuinte (cidadão que paga impostos). Isto é, as ferramentas e conteúdos não viabilizam a prestação de serviços públicos de primeira ordem (como saúde e educação). Apesar da prestação de serviço não ser uma característica predominante no primeiro grau, elementos com esta característica têm uma visibilidade significativa nos portais analisados: $77 \%$ das ferramentas de interação e conteúdo, características da prestação de serviços, estão visíveis na primeira página do portal. Esta é uma visibilidade bastante significativa quando comparamos à visibilidade de elementos com ênfase informativa - 62\%, e mais significativa ainda em relação à visibilidade na home no segundo e terceiro graus, que ficou em torno 54\%. Isto demonstra que há uma maior preocupação dos governos em dar mais visibilidade às ferramentas de serviço. 


\section{Tabela 1 \\ Elementos, conteúdos e ferramentas característicos do primeiro grau de democracia digital, localizadas nos portais}

\begin{tabular}{|l|c|}
\hline \multicolumn{1}{|c|}{ Conteúdo ou ferramenta característicos do $\mathbf{1}^{\circ}$ grau } & $\begin{array}{c}\text { \% de portais em que o elemento } \\
\text { foi localizado (no universo das } \mathbf{2 4} \\
\text { cidades analisadas) }\end{array}$ \\
\hline $\begin{array}{l}\text { Presença de informações institucionais genéricas (endereço físico e eletrônico, } \\
\text { telefones da administração, função de órgãos da administração pública) }\end{array}$ & $91,67 \%$ \\
\hline Notícias sobre a administração municipal produzidas pelo próprio governo. & $91,67 \%$ \\
\hline $\begin{array}{l}\text { Presença de informações genéricas sobre a cidade (econômicas, culturais, } \\
\text { turísticas, históricas, geográficas, étnicas) }\end{array}$ & $87,50 \%$ \\
\hline $\begin{array}{l}\text { Possibilidade de "inserção de dados" pelo usuário e conseqüente obtenção de } \\
\text { informação do tipo "consulta automatizada" - input/ output instantâneo }\end{array}$ & $87,50 \%$ \\
\hline Presença de legislação (Leis, estatutos, decretos, portarias etc.) & $87,50 \%$ \\
\hline Possibilidade de emissão de documentos oficiais & $79,17 \%$ \\
\hline Há feedback para indagação sobre tema genérico & $54,17 \%$ \\
\hline Há feedback para indagação sobre tema específico & $37,50 \%$ \\
\hline $\begin{array}{l}\text { Possibilidade de obtenção de serviço público na rua ou na região que reside o } \\
\text { cidadão, com pedido inicial realizado através do sítio }\end{array}$ & $29,17 \%$ \\
\hline Atendimento on-line instantâneo (através de chat ou ferramenta similar) & $8,33 \%$ \\
\hline $\begin{array}{l}\text { Possibilidade de obtenção de serviço público em domicílio com pedido inicial } \\
\text { realizado através do sítio }\end{array}$ & $8,33 \%$ \\
\hline Possibilidade de operação completa de serviço público via rede & \\
\hline
\end{tabular}

Um segundo aspecto importante é a deficiência de feedback informativo por parte desses veículos de comunicação on-line. Ou seja, a ênfase informativa e as potencialidades da comunicação horizontal da internet não têm repercutido efetivamente em uma horizontalidade no fluxo de informação entre estes cidadãos e seus respectivos governos. O resultado do teste de feedback governamental ${ }^{9}$, apresentado na Tabela 2, demonstra que boa parte dos governos das cidades analisadas (aproximadamente a metade) não tem preocupação em manter um canal eficiente de comunicação direta com o cidadão solicitante. Mais da metade destes portais governamentais não propiciam retorno informativo, quando

\footnotetext{
${ }^{9}$ O teste consistiu no envio de mensagens solicitando informação sobre tema que envolvia a atuação da prefeitura, sendo encaminhadas para o e-mail geral da administração ou formulário existente no portal para este fim. Buscou-se averiguar o tempo de resposta governamental para dois tipos de mensagens enviadas por dois usuários fictícios diferentes: a primeira, tratou de indagação considerada genérica e de ágil resposta; a segunda, tratou de indagação considerada mais específica que demandaria algum tipo de consulta por parte do funcionário respondente. O teste foi enviado no horário entre 9 e 10 h (horário de Brasília) em dia útil, observando o calendário de feriados municipais de cada cidade.
} 
solicitados: das 48 mensagens enviadas, 25 não obtiveram resposta ou não foi possível estabelecer o contato, ou seja, 52\% das solicitações de informações possuem problemas de feedback governamental.

Tabela 2

Teste de Feedback informativo

\begin{tabular}{|c|c|c|c|}
\hline \multirow[b]{2}{*}{ Portal } & \multirow[b]{2}{*}{ Forma de envio } & \multicolumn{2}{|c|}{ Resultado do feedback } \\
\hline & & $\begin{array}{c}\text { Pergunta sobre assunto } \\
\text { genérico* }\end{array}$ & $\begin{array}{c}\text { Pergunta sobre } \\
\text { assunto específico** }\end{array}$ \\
\hline Aracaju & Através de formulário on-line & $2^{\circ}$ & SR \\
\hline Belém & Inexistência de contato*** & ----- & ---- \\
\hline Belo Horizonte & Através de formulário on-line & $\mathrm{M}$ & $2^{\circ}$ \\
\hline Campo Grande & Através de e-mail & $\mathrm{M}$ & $\mathrm{M}$ \\
\hline Cuiabá & Através de formulário on-line & $10^{\circ}$ & SR \\
\hline Curitiba & Através de formulário on-line & SR & SR \\
\hline Florianópolis & Através de formulário on-line & $\mathrm{M}$ & SR \\
\hline Fortaleza & Através de e-mail & $4^{\circ}$ & SR \\
\hline Goiânia & Através de e-mail & $\mathrm{M}$ & $\mathrm{M}$ \\
\hline João Pessoa & Através de e-mail & $\mathrm{M}$ & SR \\
\hline Maceió & Através de formulário on-line & SR & SR \\
\hline Manaus & Através de e-mail & SR & SR \\
\hline Natal & Através de formulário on-line & SR & SR \\
\hline Palmas & Através de e-mail & SR & SR \\
\hline Porto Alegre & Através de e-mail & $\mathrm{M}$ & $2^{\circ}$ \\
\hline Porto Velho & Através de formulário on-line & SR & $\mathrm{SR}$ \\
\hline Recife & Através de e-mail & $\mathrm{M}$ & $3^{\circ}$ \\
\hline Rio Branco & Através de formulário on-line & SR & SR \\
\hline Rio de Janeiro & Através de formulário on-line & $2^{\circ}$ & $2^{\circ}$ \\
\hline Salvador & Através de e-mail & $\mathrm{M}$ & $2^{\circ}$ \\
\hline São Luís & Inexistência de contato & ---- & $----\cdot$ \\
\hline São Paulo & Através de e-mail & $\mathrm{M}$ & $3^{\circ}$ \\
\hline Teresina & Inexistência de contato & ---- & ----- \\
\hline Vitória & Através de formulário on-line & $6^{\circ}$ & $6^{\circ}$ \\
\hline
\end{tabular}

Legendas: * Foi enviada mensagem indagando qual o endereço da sede administrativa da prefeitura.

** Foi enviada mensagem indagando qual o endereço e telefone de hospital ou unidade de saúde do município que trata de doenças tropicais (esta mensagem foi enviada duas vezes em dias diferentes).

*** “Inexistência de contato" significa que o portal não possuía (no momento da pesquisa) um correio eletrônico (e-mail) geral da administração pública ou formulário para solicitar informação. Assim, nestes casos, o item não pôde ser analisado.

Resultados: $\mathrm{M}$ - resposta no mesmo dia

$2^{\circ}$ - resposta no segundo dia útil (a contar do dia de envio)

$3^{\circ}$ - resposta no terceiro dia útil (a contar do dia de envio)

$4^{\circ}$ - resposta no quarto dia útil (a contar do dia de envio)

$5^{\circ}$ - resposta no quinto dia útil (a contar do dia de envio)

$6^{\circ}$ - resposta no sexto dia útil (a contar do dia de envio)

$7^{\circ}$ - resposta do sétimo ao décimo dia útil (a contar do dia de envio)

$10^{\circ}$ - resposta do décimo dia útil por diante

$\mathrm{SR}$ - resposta acima de 1 mês ou sem resposta 
Quanto ao segundo e terceiro graus, é possível afirmar que não possuem uma existência estruturada nos portais das cidades analisadas e estão predominantemente ancorados em elementos com solidez contestável em termos de importância, quando se observa suas peculiaridades políticas. Uma análise empírica demonstra que o segundo grau existe basicamente em função da disponibilização no portal de ferramenta voltada para receber críticas, reclamações ou sugestões sem que estas sejam publicadas no portal.

\section{Tabela 3 \\ Elementos, conteúdos e ferramentas, característicos do segundo grau de democracia digital, localizadas nos portais}

\begin{tabular}{|l|c|}
\hline \multicolumn{1}{|c|}{ Conteúdo ou ferramenta característicos do $\mathbf{2}^{\mathbf{0}}$ grau } & $\begin{array}{c}\text { \% de portais em que o elemento } \\
\text { foi localizado (no universo das } \\
\text { 24 cidades analisadas) }\end{array}$ \\
\hline $\begin{array}{l}\text { Existência de sondagem de opinião NÃO-PUBLICADA: ouvidoria voltada para } \\
\text { receber opinião pública sobre determinado tema de interesse geral, mas sem } \\
\text { publicização das opiniões emitidas pelos cidadãos) }\end{array}$ & $0,00 \%$ \\
\hline $\begin{array}{l}\text { Existência de locus para recepção de críticas do cidadão NÃO-PUBLICADAS no } \\
\text { portal. }\end{array}$ & $50,00 \%$ \\
\hline $\begin{array}{l}\text { Existência de campanha publicitária on-line que estimule a emissão da opinião } \\
\text { do cidadão através do portal com link direto para formulário ou ferramenta que } \\
\text { colha esta opinião. }\end{array}$ & $0,00 \%$ \\
\hline $\begin{array}{l}\text { Sistema avançado de votação eletrônica voltado para sondagem de opinião : no } \\
\text { formato "consulta", sem efeito deliberativo. }\end{array}$ & $0,00 \%$ \\
\hline $\begin{array}{l}\text { Existência de informações no portal sobre programas (iniciativa) de inclusão } \\
\text { digital que trate de capacitação, educação ou atividades similares, visando } \\
\text { facilitar a apropriação das TICs, por parte do cidadão, enfatizando coletar a } \\
\text { opinião pública sobre questões públicas. }\end{array}$ & $4,17 \%$ \\
\hline $\begin{array}{l}\text { Existência de informações no portal sobre infra-estrutura tecnológica que } \\
\text { propicie o acesso e uso das TICs pelo cidadão, voltada para a sondagem de } \\
\text { opinião dos munícipes }\end{array}$ & $4,17 \%$ \\
\hline
\end{tabular}

Legenda: * Considerou-se "campanha publicitária" a existência de banners, pop-up ou imagens na primeira página do portal que chamem a atenção do cidadão no sentido de levá-lo a algum texto que explique e estimule esta emissão opinativa via portal.

* Considera-se "sistema avançado de votação" ferramenta disponível ao público com mecanismos personificadores, que busquem restringir 1 voto por cidadão (seja através do CPF, título de eleitor ou peculiaridade similar). As "enquetes on-line" não são consideradas neste sentido. 
Este tipo de elemento deve ser considerado pouco significativo para configurar efetivamente uma democracia digital de segundo grau. Não há, por exemplo, campanhas no portal que estimulem o input da opinião do cidadão; não há sistemas avançados de coleta de dados que possam tornar esta coleta mais bem estruturada; não há sondagens temáticas, do tipo discursiva, sobre assunto de interesse ${ }^{10}$. No caso do terceiro grau, o elemento que irá sustentar sua existência será fundamentalmente a disponibilidade de balanços financeiros e documentos de arrecadação fiscal.

Tabela 4

\section{Elementos, conteúdos e ferramentas, característicos do terceiro grau de democracia digital, localizadas nos portais}

\begin{tabular}{|c|c|}
\hline Conteúdo ou ferramenta característicos do $3^{\circ}$ grau & $\begin{array}{c}\% \text { de portais em que o elemento } \\
\text { foi localizado (no universo das } \\
24 \text { cidades analisadas) }\end{array}$ \\
\hline $\begin{array}{l}\text { Existência de locus para recepção de críticas do cidadão PUBLICADAS no } \\
\text { portal (críticas gerais, sem temas específicos) }\end{array}$ & $0,00 \%$ \\
\hline $\begin{array}{l}\text { Fórum on-line temáticos do tipo discursivo, aberto ao público mais amplo, } \\
\text { acerca de temas específicos de interesse público, com opiniões dos cidadãos } \\
\text { publicadas no portal. }\end{array}$ & $0,00 \%$ \\
\hline $\begin{array}{l}\text { Existência de pré-legislação (projetos de leis ou similares) disponíveis para } \\
\text { consulta on-line do cidadão (transparência pública quanto aos possíveis atos } \\
\text { legislativos do governo) }\end{array}$ & $0,00 \%$ \\
\hline $\begin{array}{l}\text { Possibilidade de acompanhamento financeiro ( disponibilidade de } \\
\text { documentos governamentais de arrecadação, movimentação de erário e } \\
\text { aplicação financeira dos recursos públicos - balancetes, balanços } \\
\text { financeiros) }\end{array}$ & $87,50 \%$ \\
\hline $\begin{array}{l}\text { Existência de manual, guia ou texto afim que possibilite a melhor } \\
\text { compreensão de dados financeiros disponíveis no portal para o entendimento } \\
\text { de público leigo em assuntos administrativos/ contábeis. }\end{array}$ & $0,00 \%$ \\
\hline $\begin{array}{l}\text { Existência de informações no portal sobre programas (iniciativa) de inclusão } \\
\text { digital que trate de capacitação, educação ou atividades similares, visando } \\
\text { facilitar a apropriação das TICs, por parte do cidadão, enfatizando o } \\
\text { acompanhamento público dos atos da administração pública. }\end{array}$ & $4,17 \%$ \\
\hline $\begin{array}{l}\text { Existência de informações no portal sobre infra-estrutura tecnológica que } \\
\text { propicie o acesso e uso das TICs pelo cidadão, voltada para o } \\
\text { acompanhamento público dos atos da administração pública. }\end{array}$ & $4,17 \%$ \\
\hline
\end{tabular}

\footnotetext{
10 Excluem-se aqui as chamadas "enquetes" que não representam, efetivamente, sondagens oficiais do
} tipo discursiva. 
Não há "espaço" público (do tipo fóruns on-line ou mural de críticas) onde o cidadão possa enviar, ler e comentar as críticas dos seus pares, de forma a possibilitar um grau potencialmente maior de intervenção dialógica da opinião pública, na busca de maior transparência dos atos administrativos ${ }^{11}$. A existência de documentos de arrecadação fiscal nos portais deve ser considerada um item significativo para caracterização do terceiro grau de democracia digital. Porém, o que se percebe é que esta disponibilização não é acompanhada de mecanismos que facilitem a compreensão ${ }^{12}$ ou o acesso (inclusão digital) do cidadão para utilizar tais informações, no sentido de controlar as contas do governo. Em relação a este elemento, é importante vinculá-lo à existência de um fator legal: a Lei de Responsabilidade Fiscal (LRF), em vigor no país desde o dia 5 de maio de 2000. 0 art. 48 (cap. IX, seção I) desta lei complementar estabelece que os governos executivos municipais e estaduais estão obrigados a disponibilizar em "meio eletrônico de acesso público" seus respectivos atos financeiros:

"São instrumentos de transparência da gestão fiscal, aos quais será dada ampla divulgação, inclusive em meios eletrônicos de acesso público: os planos, orçamentos e leis de diretrizes orçamentárias; as prestações de contas e o respectivo parecer prévio; o Relatório Resumido da Execução Orçamentária e o Relatório de Gestão Fiscal; e as versões simplificadas desses documentos" (BRASIL, 2000).

Aparentemente, a democracia de terceiro grau nos portais das capitais brasileiras ocorre, de modo geral, sustentada por este mecanismo constitucional obrigatório e não por um projeto de governo preocupado claramente com a transparência e que disporia todos os instrumentos possíveis para facilitar a compreensão e uso público desta prestação de contas.

Em suma, no que se refere ao segundo e terceiro graus, de forma efetiva, há pouca transparência, pouca accountability e praticamente nenhuma permeabilidade à opinião pública por parte de um Estado que potencialmente empregaria as TICs (especificamente da internet) para melhorar a participação do cidadão nos negócios públicos.

\footnotetext{
${ }^{11}$ Assim como no segundo grau, apenas o portal de Porto Alegre faz referência à programa de inclusão digital (e infra-estrutura) que pode concomitantemente ser caracterizado como de terceiro grau.

12 No que diz respeito a mecanismos de capacitação do cidadão que poderiam facilitar uma melhor compreensão dos dados disponíveis, como a configuração de uma linguagem menos técnica, ou a existência de manuais de utilização destes dados ou ainda campanhas de esclarecimento.
} 
É importante analisar a significativa ausência do quarto e quinto graus nos portais das capitais brasileiras. Não há elementos tipificadores destes dois graus. Especificamente em relação ao quarto grau, é possível encontrar, de modo bem isolado, informações sobre processos de deliberação através do chamado Orçamento Participativo ${ }^{13}$. Porém, não há referências sobre a utilização das TICs ou da internet como meio de comunicação para viabilizar a participação neste mecanismo deliberacionista. Isto leva a crer que, embora haja práticas de deliberação pública na cultura política de alguns governos, as potencialidades das TICs (neste caso, a internet) não estão sendo empregadas atualmente no Brasil para este fim. Em relação ao quinto grau, não há referência, ainda que textual, sobre elemento ou tema que possa ser vinculado às suas características. Esta ausência tão absoluta demonstra que a visão de democracia direta através do emprego das TICs, não ganhou força nos governos das capitais brasileiras. Pelo menos, ainda não está repercutindo nos portais analisados, nem mesmo a título de discurso.

Um último aspecto que deve ser observado diz respeito à precariedade de informações sobre inclusão digital. Embora seja um tema que vem ganhando a atenção do poder público, em uma tentativa de diminuir a exclusão social acirrada pelo surgimento das novas tecnologias da comunicação, quase dois terços dos portais das 24 capitais brasileiras não dispõem informações sobre o tema. Apenas 9 dos 24 portais governamentais analisados fazem alguma menção a existência de programas de inclusão digital dentro das categorias dos cinco graus estipuladas nesta pesquisa. Desses 9 portais, 7 podem ser caracterizados como programas de inclusão digital de primeiro grau, a partir das informações dispostas nos sítios. Apenas 2 portais (Belo Horizonte e Porto Alegre) podem ser caracterizados como de segundo e terceiro graus. Isto não significa concluir, necessariamente, que não haja programas de inclusão digital em andamento nestas cidades. Mas demonstra que não há uma preocupação efetiva de torná-los públicos através do portal, e isso leva a questionar se há, de fato, uma percepção concreta, por parte dos respectivos governos, da importância deste tipo de iniciativa como fundamento para o exercício de uma democracia digital.

\footnotetext{
13 O Orçamento Participativo ou similar é um mecanismo existente em alguns governos locais no Brasil, fundamentalmente criados pelo Partido dos Trabalhadores (PT). Consiste em uma abertura administrativa que estimula a reunião de cidadãos, enquanto públicos, sistematicamente, para deliberar e decidir sobre a aplicação de recursos da prefeitura, destinada a obras ou projetos de interesse geral.
} 


\section{Conclusões}

Este artigo tentou investigar se e como as tecnologias da comunicação e informação estão sendo empregadas pelos governos de importantes cidades brasileiras para fomentar a participação democrática, a partir da percepção de graus de democracia digital. É possível concluir que existem níveis de participação bastante elementares. Não há efetivas aberturas para esta participação do cidadão nos negócios públicos por parte desses governos e não há rupturas ou inovações radicalmente inovadoras neste sentido.

Em linhas gerais, algumas conclusões podem ser enumeradas: (1) a esfera governamental das maiores cidades brasileiras exercita, na atual conjuntura histórica, uma democracia digital elementar, baseada na informação ou, em segundo plano, na prestação de serviços públicos no formato delivery; neste último caso, há uma clara concentração na prestação de serviços públicos voltados para a relação tributária entre cidadão e governo; (2) não há ainda indícios de um tipo de participação política mais sofisticada no âmbito da esfera governamental das capitais brasileiras que indiquem o emprego das tecnologias da comunicação para um efetivo papel da esfera civil na produção da decisão pública: esta continua na esfera política, sem abertura efetiva de poder visando maior intervenção do cidadão comum; (3) há, atualmente, uma sub-utilização das potencialidades democráticas destas tecnologias pelos governos das maiores cidades brasileiras; e (4) há diferenças políticas pontuais quanto ao uso das TICs entre os governos das capitais, mas não se pode dizer que há diferenças estruturais importantes: fundamentalmente as cidades possuem perfis de uso bastante similar, quando analisados em linhas gerais.

Todos estes pontos indicam que, apesar do discurso de modernização dos governos, presente em boa parte dos portais, há avanços pouco significativos. Sobretudo, não há níveis importantes de participação civil a ponto de promover alterações relevantes na cultura política hoje existente. 


\section{Referências Bibliográficas}

BRASIL. Lei complementar $n^{\circ} 101$, de 4 de maio de 2000. Estabelece normas de finanças públicas voltadas para a responsabilidade na gestão fiscal e dá outras providências. Diário oficial [da] República Federativa do Brasil, Poder Executivo, Brasília, DF, 2 de maio de 2000. Seção I, art. 48.

BUCHSTEIN, H. Bytes that bite: the internet and deliberative democracy. Constellations, v. 4, n. 2, p. 248-263, 1997.

COLEMAN, S. Cutting out the middle man: from virtual representation to direct deliberation. In: HAGUE, B.; LOADER, B. D. (org.). Digital democracy: discourse and decision making in the information age. London: Routledge, 1999a. 1999b.

Can the new media invigorate democracy? The Political Quarterly, v. 70, n. 1, p. 16-22,

DAHLBERG, L. Democracy via cyberespace: mapping the rhetorics and practices of three prominent camps. New media \& society, v. 3, n. 2, p. 157-177, 2001.

DEAN, J. Why the net is not a public sphere. Constellations, v. 10, n. 1, p. 95-112, 2003.

FREY, K. Governança eletrônica: experiências de cidades européias e algumas lições para países em desenvolvimento. In: EISENBERG, J.; CEPIK, M. (org.) Internet e política: teoria e prática da democracia eletrônica. Belo Horizonte: UFMG, 2002.

GANDY, O. H. The real digital divide: citizens versus consumers. In: LIEVROUW, L. A.; LIVINGSTONE, S. (org.). Handbook of new media: social shaping and consequences of ICTs. London: Sage, 2002.

GOMES, W. Transformações da política na era da comunicação de massa. São Paulo: Paulus, 2004a.

Ciberdemocracia: possibilidades e limites. 2004. Conferência Inaugural do II Congresso Ibérico de Comunicação, Covilhã, Portugal (Inédito), 2004b.

GUTMANN, A.; THOMPSON, D. Democracy and disagreement. Cambridge: Harvard University Press, 1996. 
HAGUE, B. N.; LOADER B. D. Digital democracy: an introduction. In: HAGUE, B.; LOADER, B. D. (org.). Digital democracy: discourse and decision making in the information age. London: Routledge, 1999.

LEVY, P. As tecnologias da inteligência: o futuro do pensamento na era da informática. São Paulo: Editora 34, 1995.

Cibercultura. São Paulo: Editora 34, 1999.

LIEVROUW, L. A.; LIVINGSTONE, S. The social shaping and consequences of ICTs. In: LIEVROUW, L. A.; LIVINGSTONE, S. (org.). Handbook of new media: social shaping and consequences of ICTS. London: Sage, 2002.

MAIA, R. C. M. Redes cívicas e internet: do ambiente informativo denso às condições da deliberação pública. In: EISENBERG, J.; CEPIK, M. (org.). Internet e política: teoria e prática da democracia eletrônica. Belo Horizonte: UFMG, 2002.

MALINA, A. Perspectives on citizen democratization and alienation in the virtual public sphere. In: HAGUE, B.; LOADER, B. D. (org.). Digital democracy: discourse and decision making in the information age. London: Routledge, 1999.

MITCHELL, W. J. City of bits. 1995. Disponível em <http://mitpress2.mit.edu/ebooks/City_of_Bits/>. Acesso em 5 de jun. 2004.

E-topia: a vida urbana, mas não como a conhecemos. São Paulo: Senac, 2002.

MOORE, R. K. Democracy and cyberspace. In: HAGUE, B.; LOADER, B. D. (org.). Digital democracy: discourse and decision making in the information age. London: Routledge, 1999.

NEGROPONTE, N. A vida digital. São Paulo: Companhia das Letras, 1995.

PAPACHARISSI, Z. The virtual sphere: the internet as a public sphere. New Media \& Society, v. 4, n. 1, p. 9-27, 2002.

RHEINGOLD, H. A comunidade virtual. Lisboa: Gradiva, 1996.

RICHARD, E. Tools of governance. In: HAGUE, B.; LOADER, B. D. (org.). Digital democracy: discourse and decision making in the information age. London: Routledge, 1999. 
SCHMIDTKE, O. Berlin in the net: prospects for cyberdemocracy from above and from below. In: TSAGAROUSIANOU, R.; TAMBINI, D.; BRYAN, C. (org.) Cyberdemocracy: technology, cities and civic networks. London: Routledge, 1998.

SPINELLI, M. Democratic rhetoric and emergent media: the marketing of participatory community on radio and the Internet. International Journal of Cultural Studies, v. 3, n. 2, p. 268. $278,2000$.

TOFFLER, A. A terceira onda. São Paulo: Record, 1995.

WEBSTER, F. The information society revisited. In: LIEVROUW, L. A.; LIVINGSTONE, S. (org.). Handbook of new media: social shaping and consequences of ICTs. London: Sage, 2002.

WHILHELM, A. G. Virtual sounding boards: how deliberative is online political discussion. In: HAGUE, B.; LOADER, B. D. (org.). Digital democracy: discourse and decision making in the information age. London: Routledge, 1999.

WOLTON, D. E depois da Internet? Para uma teoria crítica dos novos mídias. Algés: Difel, 2001.

Este artigo foi baseado em pesquisa desenvolvida entre maio de 2003 e janeiro de 2005 para produção de dissertação de mestrado, defendida no Programa de Pós-Graduação em Comunicação e Cultura Contemporâneas da Universidade Federal da Bahia, com apoio do CNPq.

Recebido para publicação em junho de 2005. Aprovado para publicação em setembro de 2005. 